Letter to the Editor

\title{
Seeing the impact of the Glaucoma Inheritance Study in Tasmania (GIST) after 25 years
}

\author{
David A Mackey, ${ }^{1,2}$ Jamie E Craig ${ }^{3}$ and Alex W Hewitt ${ }^{2,4}$
}

1. Lions Eye Institute, Centre for Vision Sciences, University of Western Australia, Australia.

2. Menzies Institute for Medical Research, University of Tasmania, Australia.

3. Department of Ophthalmology, Flinders University, Flinders Medical Centre, Bedford Park, Australia.

4. Centre for Eye Research Australia, University of Melbourne, Australia.

Correspondence: David Mackey, Lions Eye Institute, Centre for Vision Sciences, University of Western Australia, Australia

Email: David.Mackey@lei.org.au

Received 9 November 2018; accepted 18 November 2018

Funding sources / Financial disclosure: NHMRC

Conflict of interest: None

This is the author manuscript accepted for publication and has undergone full peer review but has not been through the copyediting, typesetting, pagination and proofreading process, which may lead to differences between this version and the Version of Record. Please cite this article as doi: $10.1111 /$ ceo.13446

This article is protected by copyright. All rights reserved. 
Because Tasmania has good genealogy records, founder effect and low levels of immigration, it is well suited for studying inherited diseases. In the 1940s the NHMRC funded research into genetic eye disease in Tasmania. Hamilton described large pedigrees with Leber hereditary optic neuropathy with hundreds of carriers descended from a single immigrant in the convict era. ${ }^{(1)}$ Few glaucoma pedigrees were identified, in part because most cases of glaucoma are diagnosed over 50 years of age and half the glaucoma cases in the population remained undiagnosed, with many patients not informing their relatives they were being treated for glaucoma. In 1993, the GLC1A locus was identified and this accelerated research into the heritability and genetics of glaucoma. Our group initiated the Glaucoma Inheritance Study in Tasmania (GIST) in 1994. Local media, as well as the patient support group now known as Glaucoma Australia, helped raise awareness of the study. With the cooperation of all Tasmanian ophthalmologists, optometrists, general practitioners, and pharmacists, we enrolled index glaucoma cases, determined ancestry, and used Tasmanian genealogical records to connect people into pedigrees. Between 1994 and 1999, nearly 2,000 cases and 3,000 relatives were examined.

The GIST was instrumental in identifying the Myocilin gene and defining phenotypegenotype correlations ${ }^{(2)}$ in glaucoma. In addition, GIST helped determine the accuracy $^{(3)}$ and prevalence ${ }^{(4)}$ of a family history of glaucoma. Experience with the GIST led to the establishment of the Australian and New Zealand Registry of Advanced Glaucoma (ANZRAG) ${ }^{(5)}$ and, through genome-wide association studies ${ }^{(6)}$, it helped identify additional glaucoma genes.

Family history data from the GIST helped inform NHMRC guidelines for "Screening, Prognosis, Diagnosis, Management and Prevention of Glaucoma." The guidelines include recommendations for screening high-risk individuals such as first-degree 
relatives (siblings and children) of glaucoma patients, who are at 10 times greater risk for glaucoma than the general population. In 2008 the National Eye Health Demonstration Grants Program funded an extension of the GIST with a "Telemedicine Model to Prevent Blindness from Familial Glaucoma Project". This study showed that one new glaucoma case was diagnosed for every 19 first-degree relatives examined. ${ }^{(7)}$

Medicare data available from 1994/1995 through 2017/2018 for visual field testing show a quadrupling in the number of visual field tests conducted in Tasmania (from 733 services per 100,000 population to 2,732 per 100,000 population) compared with only a doubling nationally (Figure 1 ). The vast majority of visual field tests are for glaucoma. Part of the increase was due to the aging population, with Tasmania experiencing the largest increase in median age of any state over the last 20 years (from 35 years in 1997 to 42 years in 2017). Even adjusting for the increased number of Tasmanians over the age of 40, there was still a large increase in the number of visual field tests conducted in Tasmania. This increase is likely due to the enhanced awareness of the need for screening among the thousands of at-risk members of the glaucoma families in Tasmania and their health providers. The next highest rates of visual field testing are in NSW and SA, which have the highest enrolments in the ANZRAG.

"Targeting at risk relatives of glaucoma patients for early diagnosis and treatment (TARRGET)" an NHMRC Partnership grant will expand this work nationally. Ongoing work identifying the genetic markers for glaucoma (NHMRC Program grant "Translating genetic determinants of glaucoma into better diagnosis and treatment" and collaborations with the International Glaucoma Genetics Consortium) will allow us to identify family members who need ongoing examinations from those who can be discharged from regular follow-up. Although screening all high-risk relatives may 
increase the costs of surveillance, this should be recouped by the reduction of blindness.

We now know that glaucoma is one of the most heritable, common diseases ${ }^{(8)}$; many genes for Mendelian and complex forms of the disease have been identified. Glaucoma patients should be encouraged to inform their family members to seek screening. Cascade family and genetic screening protocols are being refined, which should allow us to prevent blindness, maintain quality of life, and conserve resources.

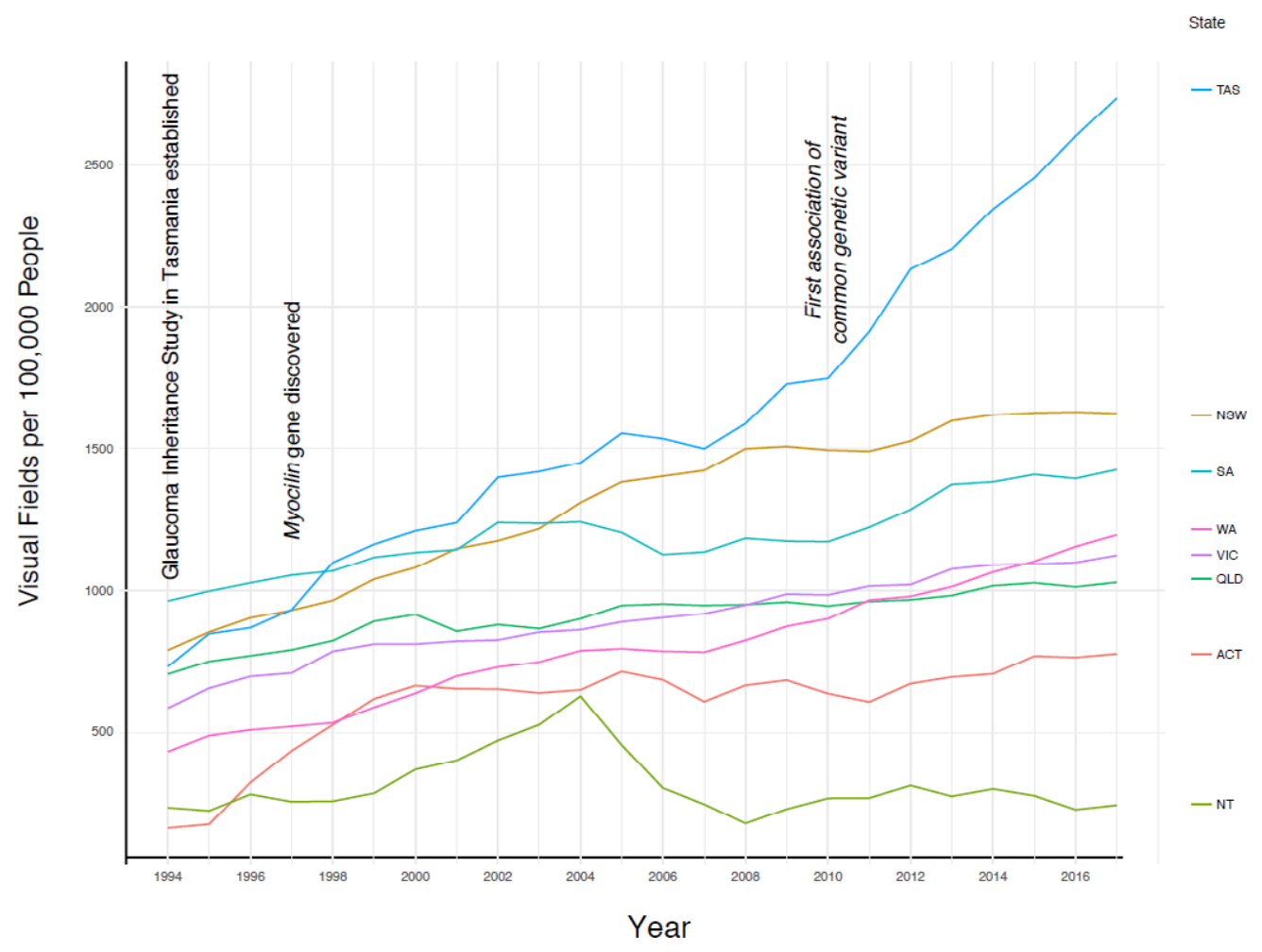

Figure 1: Visual Field Testing (which is predominantly performed for glaucoma) in procedures per 100,000 population from 1994 (the Year the GIST started) to 2017, 
by state/territory. The GIST recruitment ran from 1994-1999, while the Telemedicine Familial Glaucoma Project ran from 2008-2010. 


\section{REFERENCES}

1. Mackey DA. Genetic eye research in Tasmania: a historical overview. Clin Exp Ophthalmol. 2012;40(2):205-10.

2. Craig JE, Baird PN, Healey DL, McNaught AI, McCartney PJ, Rait JL, et al. Evidence for genetic heterogeneity within eight glaucoma families, with the GLC1A Gln368STOP mutation being an important phenotypic modifier. Ophthalmology. 2001;108(9):1607-20.

3. McNaught AI, Allen JG, Healey DL, McCartney PJ, Coote MA, Wong TL, et al. Accuracy and implications of a reported family history of glaucoma: experience from the Glaucoma Inheritance Study in Tasmania. Arch Ophthalmol. 2000;118(7):900-4. 4. Green CM, Kearns LS, Wu J, Barbour JM, Wilkinson RM, Ring MA, et al. How significant is a family history of glaucoma? Experience from the Glaucoma Inheritance Study in Tasmania. Clin Exp Ophthalmol. 2007;35(9):793-9.

5. Souzeau E, Goldberg I, Healey PR, Mills RA, Landers J, Graham SL, et al. Australian and New Zealand Registry of Advanced Glaucoma: methodology and recruitment. Clin Exp Ophthalmol. 2012;40(6):569-75.

6. Burdon KP, Macgregor S, Hewitt AW, Sharma S, Chidlow G, Mills RA, et al. Genome-wide association study identifies susceptibility loci for open angle glaucoma at TMCO1 and CDKN2B-AS1. Nat Genet. 2011;43(6):574-8.

7. Staffieri SE, Ruddle JB, Kearns LS, Barbour JM, Edwards TL, Paul P, et al. Telemedicine model to prevent blindness from familial glaucoma. Clin Exp Ophthalmol. 2011;39(8):760-5.

8. Wang K, Gaitsch H, Poon H, Cox NJ, Rzhetsky A. Classification of common human diseases derived from shared genetic and environmental determinants. Nat Genet. 2017;49(9):1319-25. 


\section{University Library}

\section{- M M N E R VA A gateway to Melbourne's research publications}

Minerva Access is the Institutional Repository of The University of Melbourne

Author/s:

Mackey, DA;Craig, JE;Hewitt, AW

Title:

Seeing the impact of the Glaucoma Inheritance Study in Tasmania after 25 years

Date:

2019-07-01

Citation:

Mackey, D. A., Craig, J. E. \& Hewitt, A. W. (2019). Seeing the impact of the Glaucoma Inheritance Study in Tasmania after 25 years. CLINICAL AND EXPERIMENTAL OPHTHALMOLOGY, 47 (5), pp.677-679. https://doi.org/10.1111/ceo.13446.

Persistent Link:

http://hdl.handle.net/11343/284905 